\title{
On the Emission Colour of the Luminescence of Hexavalent Uranium in Oxides
}

\author{
G. BLASSE
}

Physics Laboratory, Solid State Department, Utrecht University, P.O. Box 80.000, 3508 TA Utrecht, The Netherlands

(Received September 23, 1986)

\begin{abstract}
It is shown that the emission colour of the $\mathrm{U}^{6+}$ luminescence in oxides shifts gradually from green to red if the uranium coordination changes from six to four.
\end{abstract}

\section{Introduction}

The luminescence of hexavalent uranium has been known for some time and is usually studied in the uranyl complex $\mathrm{UO}_{2}{ }^{2+}[1]$. In solids octahedral $\mathrm{UO}_{6}{ }^{6-}$, tetrahedral $\mathrm{UO}_{4}{ }^{2-}$ and trigonal prismatic $\mathrm{UO}_{6}{ }^{6-}$ also occur and have been shown to luminesce $[2-6]$. Whereas the $\mathrm{UO}_{2}{ }^{2+}$ emission is always observed in the green, this is different for the other species. The emission maximum may vary from some $500 \mathrm{~nm}$ to $660 \mathrm{~nm}$ (see Table I). The luminescence of the $\mathrm{UO}_{4}{ }^{2-}$ group always seems to be in the red [5], but until now it was not possible to correlate the emission colour of the $\mathrm{U}^{6+}$ luminescence with the $\mathrm{U}^{6+}$ coordination. Using some new structural data, it now seems possible to give such a correlation. The results are presented in this paper.

\section{Experimental}

All data presented are taken from the literature. Table I presents the maxima of the emission band of the uranium luminescence in a couple of compounds. These contain either $\mathrm{W}^{6+}$ or $\mathrm{Te}^{6+}$ for which $\mathrm{U}^{6+}$ is substituted. There is also a column on the W(Te)-O distances. In the ordered perovskite $\mathrm{Ba}_{2} \mathrm{MgWO}_{6}$ the tungstate group is a regular octahedron with six equal $\mathrm{W}-\mathrm{O}$ distances. In the scheelites there is a tungstate tetrahedron with four equal $\mathrm{W}-\mathrm{O}$ distances. The examples in between need some further comments.

The crystal structure of $\mathrm{Y}_{2} \mathrm{WO}_{6}$ was not published in detail. According to ref. 11 (see also ref. 9) it contains octahedral tungstate groups with 4 shorter and 2 longer $\mathrm{W}-\mathrm{O}$ distances. The shorter bonds form a distorted tetrahedron. The same holds, as is well known [12], for the wolframite structure.

The crystal structures of $\mathrm{Sr}_{2} \mathrm{WO}_{5}, \mathrm{Ba}_{2} \mathrm{WO}_{5}$ and $\mathrm{Ba}_{2} \mathrm{TeO}_{5}$ are not known in the literature. These compounds are isomorphous [8]. Cheetham [13] was kind enough to point out to us that this structure is the same as found for $\mathrm{Cs}_{2} \mathrm{DyCl}_{5}[14]$ and $\mathrm{K}_{2} \mathrm{VO}_{2}$ $F_{3}[15]$. In fact the lattice parameters and a possible

TABLE I. Some Data on Uranium-activated Mixed Metal Oxides (see also text)

\begin{tabular}{|c|c|c|c|c|}
\hline Composition & Crystal structure & $\begin{array}{l}\text { Emission maximum } \\
(\mathrm{nm})^{*}\end{array}$ & Constitution tungstate/tellurate group & Reference \\
\hline $\mathrm{Ba}_{2} \mathrm{MgWO}_{6}-\mathrm{U}$ & $\begin{array}{l}\text { ordered } \\
\text { perovskite }\end{array}$ & 515 & $\begin{array}{l}\text { regular octahedral } \\
W-0 \sim 2.0 \AA(6 x)\end{array}$ & 7 \\
\hline $\mathrm{SI}_{2} \mathrm{WO}_{5}-\mathrm{U}$ & $\mathrm{Cs}_{2} \mathrm{DyCl}_{5}$ & 550 & & 8 \\
\hline $\mathrm{Ba}_{2} \mathrm{WO}_{5}-\mathrm{U}$ & $\mathrm{Cs}_{2} \mathrm{DyCl}_{5}$ & 560 & $W(\mathrm{Te})-04 \times$ terminal & 8 \\
\hline $\mathrm{Ba}_{2} \mathrm{TeO}_{5}-\mathrm{U}$ & $\mathrm{Cs}_{2} \mathrm{DyCl}_{5}$ & 585 & W(Te)-O $2 \times$ bridging & 8 \\
\hline $\mathrm{Y}_{2} \mathrm{WO}_{6}-\mathrm{U}$ & $\beta-\mathrm{Y}_{2} \mathrm{WO}_{6}$ & $585(\mathrm{LHeT})$ & $\begin{aligned} \mathrm{W}-0: & 4 \times 1.8 \AA \\
& 2 \times 2.2 \AA\end{aligned}$ & 9 \\
\hline $\mathrm{MgWO}_{4}-\mathrm{U}$ & wolframite & 585(LHeT) & $\mathrm{W}-\mathrm{O}: 4 \times 1.80-1.90 \AA$ & 9 \\
\hline $\mathrm{CaWO}_{4}-\mathrm{U}$ & wolframite & $\sim 625(\mathrm{LNT})$ & $2 \times 2.2 \AA$ & 10 \\
\hline $\mathrm{CaWO}_{4}-\mathrm{U}$ & scheelite & 645(LHeT) & $\mathrm{W}-\mathrm{O} 4 \times 1.79 \AA$ & 5 \\
\hline $\mathrm{SrWO}_{4}-\mathrm{U}$ & scheelite & $660(\mathrm{LHeT})$ & $\mathrm{W}-\mathrm{O} 4 \times 1.78 \mathrm{~A}$ & 5 \\
\hline $\mathrm{BaWO}_{4}-\mathrm{U}$ & scheelite & $660(\mathrm{LHeT})$ & $\mathrm{W}-04 \times 1.78 \AA$ & 5 \\
\hline
\end{tabular}

${ }^{*}$ At $300 \mathrm{~K}$, unless indicated otherwise (LNT = liquid nitrogen temperature; LHeT = liquid helium temperature). 
space group of $\mathrm{Ba}_{2} \mathrm{TeO}_{5}$ [16] are similar to those for $\mathrm{K}_{2} \mathrm{VO}_{2} \mathrm{~F}_{3}$ and $\mathrm{Cs}_{2} \mathrm{DyCl}_{5}$. In this structure there are infinite chains formed by linking tungstate octahedra together (taking $\mathrm{Ba}_{2} \mathrm{WO}_{5}$ as an example) via cis-bridging oxygen ions. In this way we obtain a zig-zag chain of corner-sharing tungstate octahedra. This structure is in good agreement with the predictions made from vibrational spectroscopy results [8].

In this way the $\mathrm{W}^{6+}$ ion is coordinated by four terminal and 2 bridging oxygen ions. The former are expected to have a shorter distance to $\mathrm{W}^{6+}$ than the latter. This is actually observed in the cases of $\mathrm{Cs}_{2} \mathrm{DyCl}_{5}$ (Dy-Cl: 2.58-2.64 $\AA$, terminal, and 2.74 $\AA$, bridging) [14] and $\mathrm{K}_{2} \mathrm{VO}_{2} \mathrm{~F}_{3}(\mathrm{~V}-\mathrm{F}: 1.86$ and $1.91 \AA$, terminal, and $2.19 \AA$, bridging) [15]. In this structure the $\mathrm{W}^{6+}$ or $\mathrm{Te}^{6+}$ ion is, therefore, expected to have 4 shorter and 2 longer W(Te)-O distances.

\section{Discussion}

\section{The $U^{6+}$ Emission Colour}

From Table I, it can be seen that the emission colour of the uranium luminescence varies gradually from green to deep red. Simultaneously the host lattice group involved changes from regular octahedral to tetrahedral. The lattice change occurs gradually because the intermediary examples have a host lattice group with 4 shorter and 2 longer distances. This change is also reflected in the vibrational spectra as noted earlier by us [17]. With Table $I$ in mind we will now reconsider the relation between emission colour of the uranium luminescence and the uranium coordination.

The $\mathrm{UO}_{2}{ }^{2+}$ emission is in the green. Small spectral variations are possible due to changes in the equatorial ligands [1]. The emission of the regular $\mathrm{UO}_{6}{ }^{6-}$ group is in the green-yellow. The exact position depends on the ions in the second coordination sphere [7] which seem to play a role comparable to that of the equatorial ligands in the case of the uranyl group. The role of this second coordination sphere appears to be somewhat more marked: by varying the alkaline earth ions in the ordered perovskite structure the emission maximum may be varied from $505 \mathrm{~nm}\left(\mathrm{Sr}_{2} \mathrm{MgWO}_{6}-\mathrm{U}\right)$ to $545 \mathrm{~nm}$ (BaLaNa$\left.\mathrm{WO}_{6}{ }^{-} \mathrm{U}\right)$ [7]. For the $\mathrm{UO}_{2}{ }^{2+}$ and the $\mathrm{UO}_{6}{ }^{6-}$ cases orbital energy calculations have nowadays successfully been performed $[1,3]$.

The $\mathrm{UO}_{4}{ }^{2-}$ group emits undoubtedly in the far red [5]. Why this emission is at so long a wavelength cannot be understood at the moment. The electronic structure of uranate complexes is complicated. For the tctrahedral case no calculations have been performed upto now. The present work solves the problem that there are orange-emitting uranium phosphors, like $\mathrm{Ba}_{2} \mathrm{TeO}_{5}-\mathrm{U}$, where the $\mathrm{U}^{6+}$ ion seems to be in octahedral coordination. There cannot be much doubt that the uranium emission shifts to a longer wavelength if the tungstate (tellurate) complex of the host lattice distorts in such a way that the coordination becomes pseudotetrahedral, i.e. 4 shorter and 2 longer bonds. This implies that the $\mathrm{U}^{6+}$ ion shows the same or a similar coordination as the hexavalent host lattice ion. It is, in our opinion, a matter of taste, whether one describes this situation as a pseudo-tetrahedral $\mathrm{UO}_{4}{ }^{2-}$ group (with two other $\mathrm{O}^{2-}$ ions nearby) or as an extreme second sphere effect (the distortions considered are due to the way the tungstate octahedra are coupled together).

\section{Predictions}

If the correlation made above is assumed to be correct, it should be possible to use the position of the emission maximum to predict the coordination of the hexavalent ions. We apply this to a few cases.

(i) $\mathrm{Li}_{2} \mathrm{WO}_{4}-\mathrm{U}$ shows a uranium emission with a maximum at about $550 \mathrm{~nm}$ [18]. The host lattice has phenacite structure with tetrahedral $\mathrm{WO}_{4}{ }^{2-}$ groups. The $\mathrm{U}^{6+}$ ion can, therefore, not occupy the $\mathrm{W}^{6+}$ sites, since this is expected to yield red emission. The phenacite structure has empty channels with octahedra] sites. Actually, 4 distances from the centre to the $\mathrm{O}^{2-}$ ions are shorter than the other 2 . We predict, therefore, that the $\mathrm{U}^{6+}$ ions enter the channels, not the $\mathrm{W}^{6+}$ sites. In fact the $\mathrm{U}^{6+}$ ion is too large for tetrahedral coordination as is also clear from the restricted amount of $\mathrm{U}^{6+}$ ions which can be introduced into the scheelites [5].

(ii) In the series $\mathrm{Sr}_{2} \mathrm{WO}_{5}-\mathrm{U}, \mathrm{Ba}_{2} \mathrm{WO}_{5}-\mathrm{U}$ and $\mathrm{Ba}_{2} \mathrm{TeO}_{5} \mathrm{U}$ the uranium emission shifts to the red. This suggests that the difference between the two sets of unequal $\mathrm{W}^{6+}\left(\mathrm{Te}^{6+}\right)-\mathrm{O}^{2-}$ distances increases in this sequence. A structure refinement of these three structures is necessary to confirm this statement.

(iii) A similar argument holds for the wolframites $\mathrm{MgWO}_{4}, \mathrm{ZnWO}_{4}$ and $\mathrm{CdWO}_{4}$. Table II shows how well the relation holds within a series of compounds with the same crystal structure. If the ratio between the longer and shorter $\mathrm{W}-\mathrm{O}$ distances increases, the emission maximum of the uranium luminescence in these host lattices shifts to longer wavelengths.

\section{Host Lattice Emission of the Compounds with $\mathrm{Cs}_{2} \mathrm{DyCl}_{5}$ Structure}

Now the structures are known, we would like to reconsider the absence of luminescence, even at 4.2 $\mathrm{K}$, in the undoped $\mathrm{Sr}_{2} \mathrm{WO}_{5}$ and $\mathrm{Ba}_{2} \mathrm{WO}_{5}$ [8]. This is a remarkable observation since many tungstates are known to luminescence [22]. We will now show that it is the chain formation which is responsible for this fact. It has been argued that under certain con. ditions the tungstate (or titanate, niobate) orbitals 
TABLE II. Data on the Tungstate Group and the $\mathrm{U}^{6+}$ Luminescenece in some Wolframites

\begin{tabular}{|c|c|c|c|c|c|}
\hline \multirow[t]{2}{*}{ Host lattice } & \multirow{2}{*}{$\begin{array}{l}\text { W-O distances } \\
(\AA)\end{array}$} & \multirow[t]{2}{*}{$1 / s^{a}$} & \multirow{2}{*}{$\begin{array}{l}\text { Emission maximum } \mathrm{U}^{6+} \\
(\mathrm{nm})\end{array}$} & \multicolumn{2}{|c|}{ References } \\
\hline & & & & Structure & Luminescence \\
\hline $\mathrm{MgWO}_{4}$ & $\begin{array}{l}1.80(2 x) \\
1.89(2 x) \\
2.14(2 x)\end{array}$ & 1.16 & 585 & 19 & 9,10 \\
\hline $\mathrm{ZnWO}_{4}$ & $\begin{array}{l}1.83(2 x) \\
1.84(2 x) \\
2.18(2 x)\end{array}$ & 1.19 & 610 & 20 & 10 \\
\hline $\mathrm{CdWO}_{4}$ & $\begin{array}{l}1.80(2 x) \\
1.87(2 x) \\
2.20(2 x)\end{array}$ & 1.20 & 625 & 21 & 10 \\
\hline
\end{tabular}

a Ratio between the longer $\mathrm{W}-\mathrm{O}$ distance and the average of the two shorter ones.

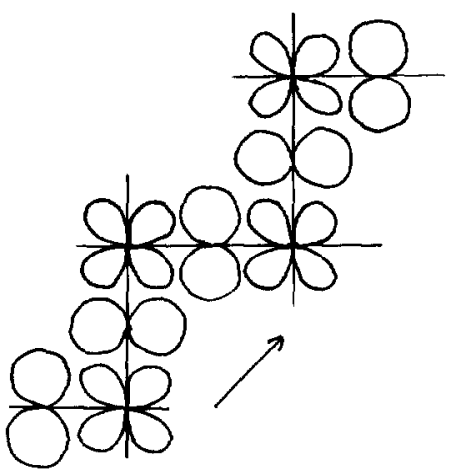

Fig. 1. $\pi$ Bonding in the $\mathrm{WO}_{5}{ }^{4-}$ chain of $\mathrm{Ba}_{2} \mathrm{WO}_{5}$ (schematic). The arrow indicates the chain direction. Wavefunctions with two lobes represent $2 p$ orbitals at the oxygen sites, those with four lobes $5 \mathrm{~d}\left(\mathrm{t}_{2}\right)$ orbitals at the tungsten sites.

may overlap each other so that energy hand formation occurs [23]. The excited state shows a high mobility which brings the excitation energy to killer sites where it is lost nonradiatively. If this effect occurs, the optical absorption edge is expected at low energies (due to broad-band formation) and the emission, if observable at all, should have a small Stokes shift. This is what has been observed:

(i) The absorption edge of, for example, $\mathrm{Ba}_{2} \mathrm{WO}_{5}$ is at about $30000 \mathrm{~cm}^{-1}$ [8], to be compared with $41000 \mathrm{~cm}^{-1}$ for $\mathrm{BaWO}_{4}$ [24] and $33000 \mathrm{~cm}^{-1}$ for $\mathrm{Ba}_{3} \mathrm{WO}_{6}[25]$.

(ii) For $\mathrm{Ba}_{2} \mathrm{TeO}_{5}-\mathrm{W}$ a weak luminescence was observed at $4.2 \mathrm{~K}$. The broad emission band has a maximum at $480 \mathrm{~nm}$ [8]. This implies a Stokes shift of about $1 \mathrm{eV}$, whereas the usual value is about $2 \mathrm{eV}$ [22].

It seems justified, therefore, to assume that the band model applies to $\mathrm{Ba}_{2} \mathrm{WO}_{5}$. If one considers the linear $\mathrm{WO}_{5}{ }^{4-}$ chain, this becomes immediately clear. Band formation occurs via $\pi$ bonding between one of the $d\left(t_{2}\right)$ orbitals of the tungsten ion and a suitable $\mathrm{p}$ orbital of the oxygen ions (see Fig. 1). Using the higher $d(e)$ orbitals of tungsten, it is also possible to form a band by $\sigma$ bonding. Although this band formation prevents luminescence, it cannot be excluded that it leads to interesting other properties in view of its one-dimensional character.

\section{Acknowledgement}

The author is indebted to Dr. A. K. Cheetham who drew his attention to the isomorphism between $\mathrm{Ba}_{2} \mathrm{TeO}_{5}$ and $\mathrm{Cs}_{2} \mathrm{DyCl}_{5}$.

\section{References}

1 C. K. Jфrgensen and R. Reisfeld, Struct. Bonding (Berlin), 50,119 (1982).

2 G. Blasse, J. Electrochem. Soc., 124, 1280 (1977).

3 K. C. Bleijenberg, Struct. Bonding (Berlin), 42, 97 (1980).

4 G. Blasse, K. C. Bleijenberg and D. M. Krol, J. Lumin., $18 / 19,57$ (1979).

5 R. U. E. 't Lam and G. Blasse, J. Chem. Phys., 72, 1803 (1980).

6 G. Blasse, G. J. Dirksen and L. H. Brixner, J. Solid State Chem., 44, 162 (1982).

7 J. Th. W. de Hair and G. Blasse, J. Solid State Chem., 19. 263 (1976).

8 G. Blasse and G. P. M. van den Heuvel, J. Lumin., 8, 406 (1974).

9 G. Blasse, G. P. M. van den Heuvel and J. J. A. van Hesteren, J. Solid State Chem., 2199 (1977).

$10 \mathrm{~F}$. A. Kröger, 'Some Aspects of the Luminescence of Solids', Elsevier, Amsterdam, 1948.

11 J. L. W. van der Does de Bije, J. L. Sommerdijk, J. Hornstra, A. Bril and A. L. N. Stevels, J. Lumin., 18/19. 285 (1979).

12 O. Muller and R. Roy, 'The Major Ternary Structural Families', Springer, Berlin, 1974.

13 A. K. Cheetham, 3rd European Conf. Solid State Chem., 
Regensburg, May 1986, invited lecture; private communication.

14 G. Meyer, Z. Anorg. All. Chem., 469, 149 (1980).

15 R. R. Ryan, S. H. Mastin and M. J. Reisfeld, Acta Crystallogr., Sect. B, 27, 1270 (1971).

16 S. Natansohn, J. Electrochem. Soc., 120, 660 (1973).

17 G. Blasse, J. Inorg. Nucl. Chem., 37, 97 (1975).

18 G. Blasse and G. P. M. van de Heuvel, Phys. Status Solidi A, 39, K157 (1977).

19 O. S. Filipenko, E. A. Pobedimskaya, V. I. Ponomarev and N. V. Belov, Kristallografiya, 13, 1073 (1968).

20 O. S. Filipenko, E. A. Pobedimskaya and N. V. Belov, Kristallografiya, 13, 163 (1968).
21 A. V. Chichagov, V. V. Ilyukhin and N. V. Belov, Dokl. Akad. Nauk SSSR, 166, 87 (1966).

22 G. Blasse, Struct. Bonding (Berlin), 42, 1 (1980).

23 G. Blasse, Rev. Inorg. Chem., 5, 319 (1983); L. G. J. de Haart, A. J. de Vries and G. Blasse, J. Solid State Chem., 59, 291 (1985); H. C. G. Verhaar, H. Donker, G. J. Dirksen, M. J. J. Lammers, G. Blasse, C. C. Torardi and L. H. Brixner, J. Solid State Chem., 60, 20 (1985).

24 G. Blasse and W. J. Schipper, Phys. Status Solidi A, 25, K163 (1974).

25 A. B. van Oosterhout, Phys. Status Solidi A, 4I, 607 (1977); Thesis. University Utrecht, 1976. 